\title{
Effect of High Heat Input on Toughness and Microstructure of Coarse Grain Heat Affected Zone in Zr Bearing Low Carbon Steel
}

\author{
Minghao SHI, ${ }^{*}$ Pengyan ZHANG, Chao WANG and Fuxian ZHU \\ State Key Laboratory of Rolling Technology and Automation, Northeastern University, Shenyang, 110819 China. \\ (Received on September 10, 2013; accepted on December 27, 2013)
}

\begin{abstract}
Microstructure evolution and impact toughness of simulated coarse grained heat affected zone (CGHAZ) in $\mathrm{Zr}$ bearing low carbon steel have been investigated in this study. Thermal simulator was used to simulate microstructure evolution of CGHAZ with high heat input welding thermal cycle at $1400^{\circ} \mathrm{C}$ peak temperature. Microstructure of CGHAZ consisted of high volume fraction of AF inside grain and GBF at prior austenite grain boundaries. Prior austenite grain size of CGHAZ increases with heat input increasing. Excellent impact toughness (more than $100 \mathrm{~J}$ ) of CGHAZ with heat input of $1000 \mathrm{~kJ} / \mathrm{cm}$ was obtained in this experiment. Impact toughness of CGHAZ with $400 \mathrm{~kJ} / \mathrm{cm}(230 \mathrm{~J})$ is the highest, because austenite grain size of CGHAZ with $400 \mathrm{~kJ} / \mathrm{cm}$ favors the development of AF inside grain. Impact toughness is not only related with high angle boundaries but also with effective grain size. High supercooling of CGHAZ provided driving force for the AF transformation during welding thermal cycle, increasing the number of AF.
\end{abstract}

KEY WORDS: coarsen grained heat affected zone (CGHAZ); acicular ferrite (AF); impact toughness; microstructure; electron backscattered diffraction (EBSD).

\section{Introduction}

In order to enhance welding efficiency and reduce welding costs, high heat input welding process was applied in HSLA steels. The balance of high strength and good toughness in HSLA steels can be upset by welding thermal cycle characterized by rapid heating and high peak temperature, producing poor impact toughness at heat affected zone (HAZ), especially coarsen grained heat affected zone (CGHAZ) adjacent to the weld fusion line experiencing peak temperature up to $1400^{\circ} \mathrm{C}$ or higher. ${ }^{1)}$

It is generally recognized that microstructure consisting of mainly acicular ferrite (AF) provides optimum weld metal and CGHAZ mechanical properties in viewpoint of strength and toughness. ${ }^{2)}$ The addition of TiN to steels is widely used to improve toughness in CGHAZ through pinning austenite grain boundaries and promoting AF transformation during welding thermal cycle. ${ }^{3)}$ However, it is reported that dissolution of TiN particles at higher temperature $\left(1400^{\circ} \mathrm{C}\right)$ may result in loss in grain refinement capability of TiN. ${ }^{4)}$ Oxide metallurgy has a beneficial effect on the improvement of toughness in CGHAZ with high heat input welding thermal cycle because of high dissolution point and greater thermal stability.,5)

Relation of toughness and microstructure in CGHAZ with high heat input welding thermal cycle in Zr-bearing lowcarbon steels is seldom studied. In this present study, specimens were subjected to different high heat input welding

\footnotetext{
* Corresponding author: E-mail: minghao207@gmail.com

DOI: http://dx.doi.org/10.2355/isijinternational.54.932
}

thermal cycle at $1400^{\circ} \mathrm{C}$ peak temperature to simulated microstructure transformation in CGHAZ, excellent impact toughness with high heat input was obtain at CGHAZ, especially heat input of $1000 \mathrm{~kJ} / \mathrm{cm}$. We present results concerning the detailed effect of welding heat input on impact toughness and microstructure transformation at CGHAZ.

\section{Experimental Procedure}

\subsection{Specimen Preparation}

Experimental steels were made by use of vacuum induction melting furnace. The chemical composition of steel is: 0.08 C, 0.26 Si, 1.5 Mn, 0.005 S, 0.008 P, 0.008 Zr, 0.015 Ti, $0.0039 \mathrm{~N}, 0.02 \mathrm{~V}$ and $0.01 \mathrm{Nb}$ (wt.\%). The $100 \mathrm{~mm} \times 100 \mathrm{~mm}$ ingot was reheated to $1200^{\circ} \mathrm{C}$ for $2 \mathrm{~h}$, and rolled into $16 \mathrm{~mm}$ plate by thermo-mechanical control processing (TMCP) in the recrystallized zone and the non-recrystallized zone with cooling rate of $15-20^{\circ} \mathrm{C} / \mathrm{s}$, final cooling temperature of $650^{\circ} \mathrm{C}$. And the as-rolled mechanical properties are as follows: yield strength $435 \mathrm{MPa}$, ultimate tensile strength $543 \mathrm{MPa}$, elongation $29 \%$ and average impact toughness $298 \mathrm{~J}\left(-20^{\circ} \mathrm{C}\right)$.

\subsection{High Heat Input Welding Thermal Cycle Proce- dure}

High heat input welding thermal cycle simulations were conducted on a thermo-mechanical simulator to study microstructure evolution and impact toughness changes in the CGHAZ. Simulated specimens were cut along the transversal direction of hot rolled steel plate and machined into dimensions $11 \mathrm{~mm} \times 11 \mathrm{~mm} \times 55 \mathrm{~mm}$ for CGHAZ simula- 
tions. High heat input welding thermal cycle was determined by the Rykalin mathematical heat transfer model to simulate the welding process. ${ }^{6)}$ The thermal cycle of the welding simulation is characterized by the peak temperature

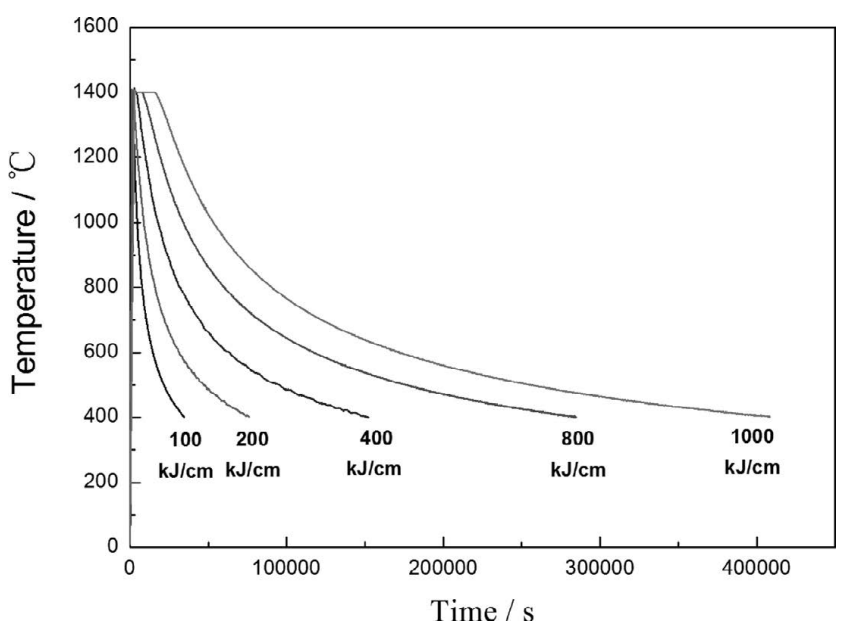

Fig. 1. Schematic diagram of welding thermal cycle.
$\left(\mathrm{T}_{\mathrm{p}}\right)$, cooling time from $800^{\circ} \mathrm{C}$ to $500^{\circ} \mathrm{C}\left(\Delta \mathrm{t}_{800-500}\right)$ and heat input energy $(\mathrm{E})$. The high heat input welding thermal cycle parameter and curves is schematically shown in Fig. 1 and Table 1. The specimens were rapidly heated to peak temperature $\left(\mathrm{T}_{\mathrm{p}}\right)$ of $1673 \mathrm{~K}\left(1400^{\circ} \mathrm{C}\right)$ with heating rate of $100^{\circ} \mathrm{C} / \mathrm{s}$ and cooled at different cooling time for range of $800^{\circ} \mathrm{C}$ to $500^{\circ} \mathrm{C}$ to be equivalent to welding heat input of $100 \mathrm{~kJ} / \mathrm{cm}, 200 \mathrm{~kJ} / \mathrm{cm}, 400 \mathrm{~kJ} / \mathrm{cm}, 800 \mathrm{~kJ} / \mathrm{cm}$ and $1000 \mathrm{~kJ} / \mathrm{cm}$.

\subsection{Impact Toughness Tests}

After CGHAZ simulation, the specimens were machined

Table 1. Parameter of high heat input welding thermal cycle.

\begin{tabular}{cccc}
\hline $\begin{array}{c}\text { Peak Temp. } \\
\left({ }^{\circ} \mathrm{C}\right)\end{array}$ & $\begin{array}{c}\text { Holding Time at } \\
\text { Peak Temp. }(\mathrm{sec})\end{array}$ & $\begin{array}{c}\Delta \mathrm{t}_{800-500} \\
(\mathrm{sec})\end{array}$ & $\begin{array}{c}\text { Heat Input } \\
(\mathrm{kJ} / \mathrm{cm})\end{array}$ \\
\hline 1400 & 1 & 137.5 & 100 \\
1400 & 1 & 214 & 200 \\
1400 & 3 & 325 & 400 \\
1400 & 30 & 730 & 800 \\
1400 & 60 & 818 & 1000 \\
\hline
\end{tabular}

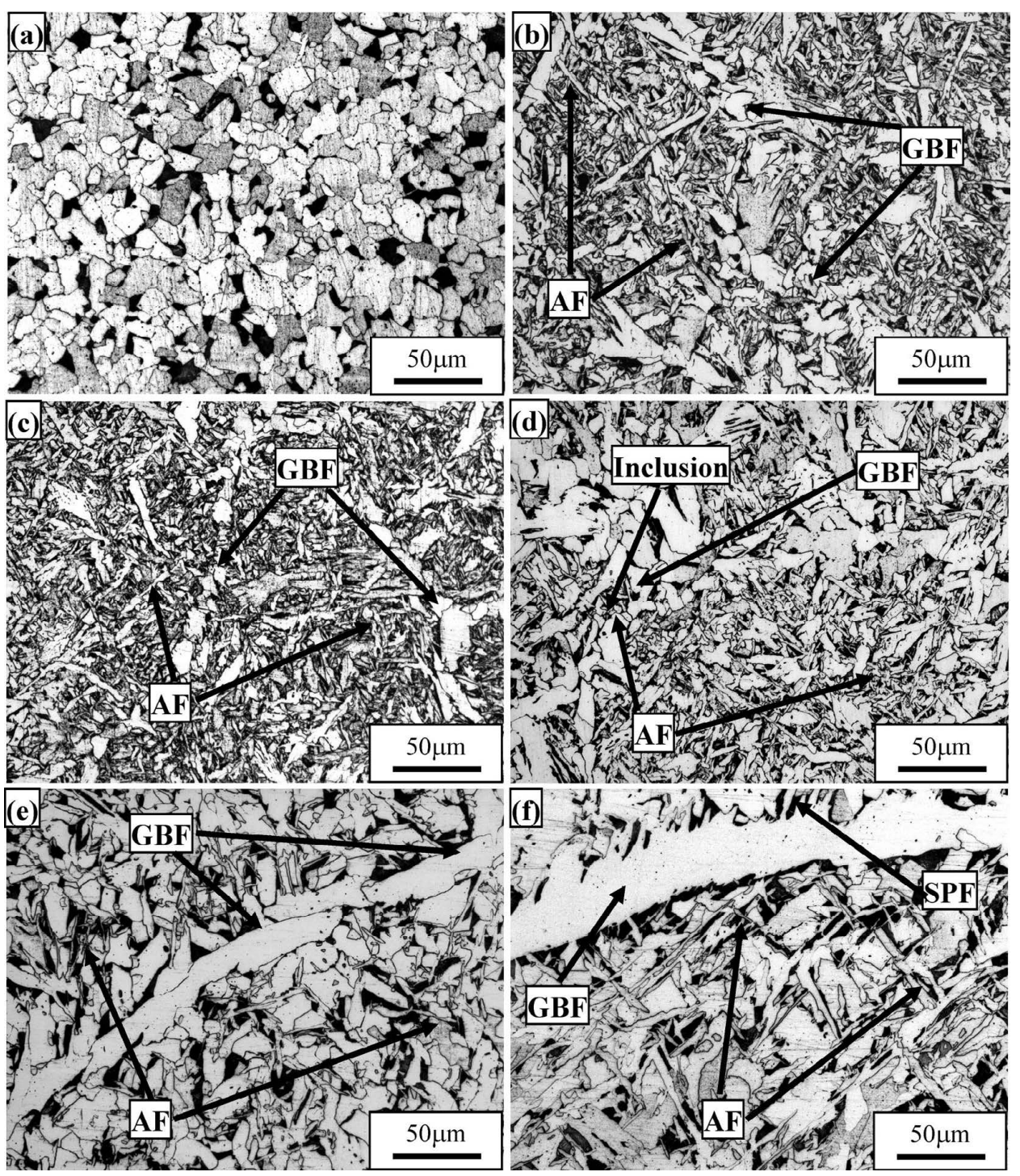

Fig. 2. Microstructure of base metal and CGHAZ with different heat input welding thermal cycle, (a) base metal, (b) $100 \mathrm{~kJ} / \mathrm{cm}$, (c) $200 \mathrm{~kJ} / \mathrm{cm}$, (d) $400 \mathrm{~kJ} / \mathrm{cm}$, (e) $800 \mathrm{~kJ} / \mathrm{cm}$ and (f) $1000 \mathrm{~kJ} / \mathrm{cm}$. 
into standard Charpy-V-notch samples with dimensions $10 \mathrm{~mm} \times 10 \mathrm{~mm} \times 55 \mathrm{~mm}$ and then subjected to impact tests at $-20^{\circ} \mathrm{C}$ on an Instron Dynatup 9200 series instrumented drop weight impact tester.

\subsection{Metallographic Observations}

The metallographic observation region was fixed near the monitoring thermocouple and then polished using standard metallographic procedures and etched with 3 vol\% Nital in order to reduce the error resulting from relatively uneven cooling rate. The microstructure of CGHAZ was examined using optical microscopes (OM). And prior austenite grain size was measured with the line intercept method based on low magnification OM. Fracture surface observation and crystallographic orientation feature analysis were carried out by use of scanning electron microscopy (SEM) equipped with an electron backscattered diffraction (EBSD) system. The scanned area for EBSD analyses is about $250 \mu \mathrm{m} \times$ $250 \mu \mathrm{m}$ with scanning step of $1 \mu \mathrm{m}$.

\section{Experimental Results}

\subsection{Microstructure of Base Metal and CGHAZ}

Figure 2 shows optical micrographs of base metal and CGHAZ with high heat input welding thermal cycle. Microstructures of base metal were mainly composed by ferrite and pearlite. Microstructure of CGHAZ consisted of high volume fraction of AF inside grain and grain boundaries ferrite $(\mathrm{GBF})$ at prior austenite grain boundaries. It is noted that small volume fraction of side plate ferrite (SPF) growing into grain at austenite grain boundaries was observed at CGHAZ with heat input of $1000 \mathrm{~kJ} / \mathrm{cm}$, as shown in Fig. 2(f), because of long time cooling from $800^{\circ} \mathrm{C}$ to $500^{\circ} \mathrm{C}$, which is favorable to element diffusion during transformation. It should be point out that although supersaturation drive SPF nucleation at grain boundaries, ${ }^{7)}$ the supersaturation is also favorable to $\mathrm{AF}$ nucleation inside gain when the time cooling from $800^{\circ} \mathrm{C}$ to $500^{\circ} \mathrm{C}$ is short. AF transformation time is very short relative to the time SPF transformation. ${ }^{8)}$ AF firstly nucleated inside grain during cooling, occupying most nucleating space, inhibiting SPF nucleation at gain boundaries. Therefore, small volume fraction of SPF observed at the side of which the number of AF is small in the specimen with heat input of $1000 \mathrm{~kJ} / \mathrm{cm}$.

Figure 3 shows variation of austenite grain size of CGHAZ with high heat input welding thermal cycle. It can be found that austenite grain size of CGHAZ increases with heat input increasing due to long holding time at peak temperature, as shown in Table 1.

\subsection{Impact Toughness of Base Metal and CGHAZ}

Figure 4 shows Charpy impact toughness of base metal and CGHAZ with different heat input welding thermal cycle tested at $-20^{\circ} \mathrm{C}$. Excellent impact toughness (more than $100 \mathrm{~J}$ ) of CGHAZ with heat input of $1000 \mathrm{~kJ} / \mathrm{cm}$ was obtained in this experiment. It is noted that impact toughness of CGHAZ with $400 \mathrm{~kJ} / \mathrm{cm}(230 \mathrm{~J})$ is the highest, because austenite grain size of CGHAZ with $400 \mathrm{~kJ} / \mathrm{cm}$ favors the development of AF inside grain, contributing to refinement of microstructure of CGHAZ. A coarser austenite grain size to reduce grain boundary surface area may then be required in order to shift the balance of ferrite nucleation from the austenite grain boundaries to the intragranular regions (assuming inclusions are inert substrates) because of long holding time at peak temperature, so that high volume fraction of AF are kinetically favorable. It can be found that when heat input is more than $400 \mathrm{~kJ} / \mathrm{cm}$, the impact toughness significantly decreased, because of further increased austenite grain size to more than a critical value. This result is consistent with the conclusions proposed by Lee and Pan, ${ }^{9)}$ who have reported that the volume fraction of AF begin to be reduced with further increased austenite grain size to more than a critical value in Ti-killed steels without and with addition of $\mathrm{Ca}$. And they founded that the cover of $\mathrm{CaO}$ on the surface layer of Ti-oxides enlarged the disregistry between inclusions and ferrite and reduced the strain field set up in austenite around inclusions. However, it should be pointed out that the critical value of austenite grain size for AF transformation can be different for various steel grades.

Figure 5 shows fracture surface of CGHAZ with $400 \mathrm{~kJ} / \mathrm{cm}$ and $1000 \mathrm{~kJ} / \mathrm{cm}$. It is found that fracture surface of CGHAZ with $400 \mathrm{~kJ} / \mathrm{cm}$ exhibited dimple fracture mode, which allows CGHAZ with $400 \mathrm{~kJ} / \mathrm{cm}$ to absorb more energy dur-

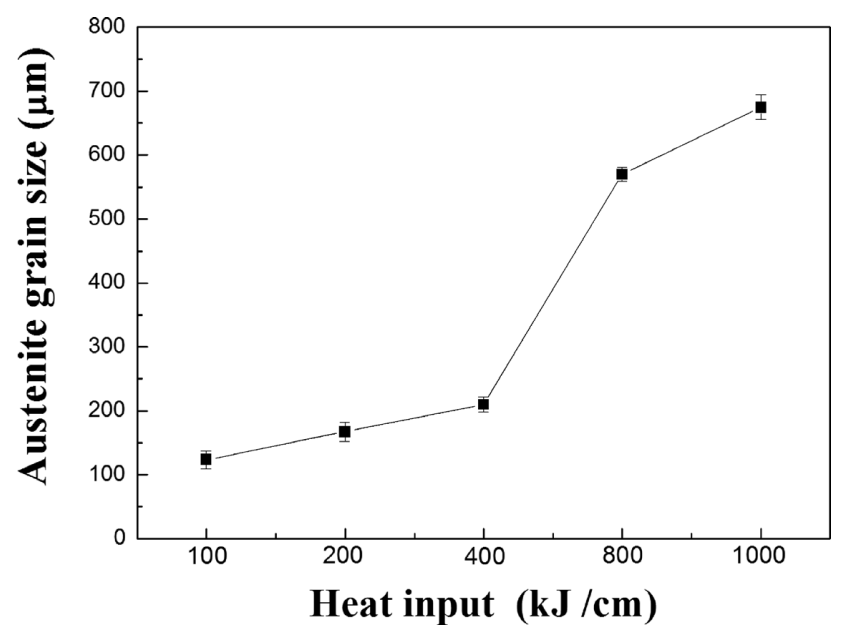

Fig. 3. Austenite grain size of CGHAZ with heat input of $100 \mathrm{~kJ} / \mathrm{cm}$, $200 \mathrm{~kJ} / \mathrm{cm}, 400 \mathrm{~kJ} / \mathrm{cm}, 800 \mathrm{~kJ} / \mathrm{cm}$ and $1000 \mathrm{~kJ} / \mathrm{cm}$.

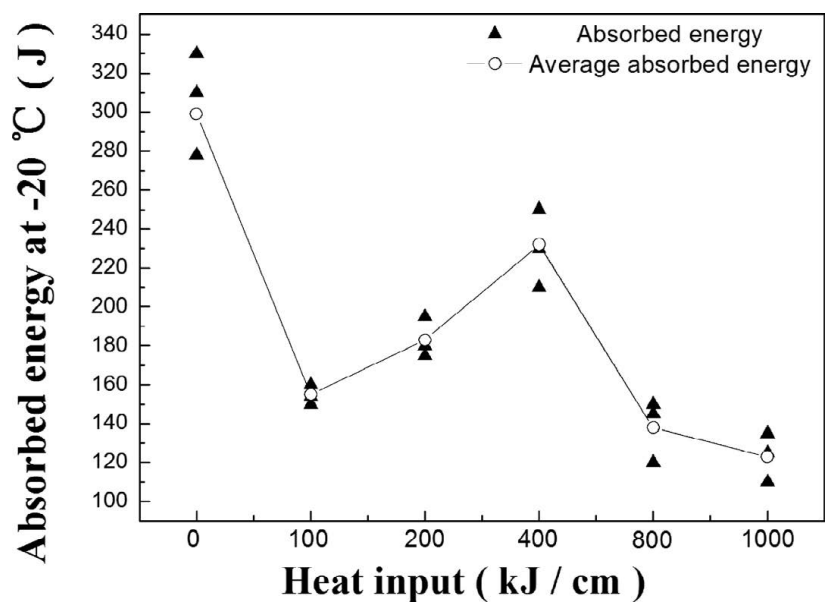

Fig. 4. Charpy impact toughness of base metal and CGHAZ with heat input of $100 \mathrm{~kJ} / \mathrm{cm}, 200 \mathrm{~kJ} / \mathrm{cm}, 400 \mathrm{~kJ} / \mathrm{cm}, 800 \mathrm{~kJ} / \mathrm{cm}$ and $1000 \mathrm{~kJ} / \mathrm{cm}$ 

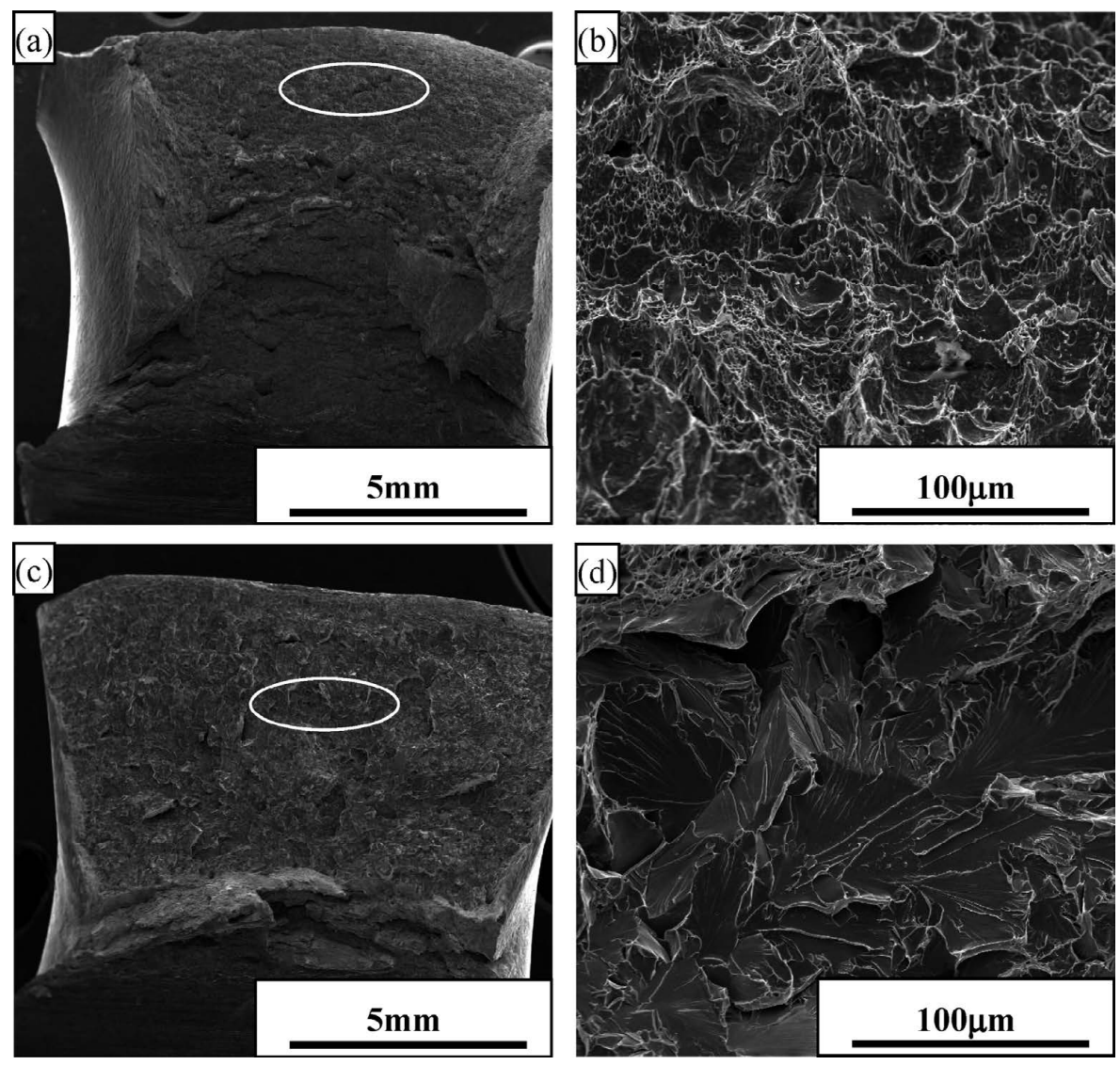

Fig. 5. Morphologies of fracture surface at CGHAZ with heat input of (a), (b) $400 \mathrm{~kJ} / \mathrm{cm}$ and (c), (d) $1000 \mathrm{~kJ} / \mathrm{cm}$.

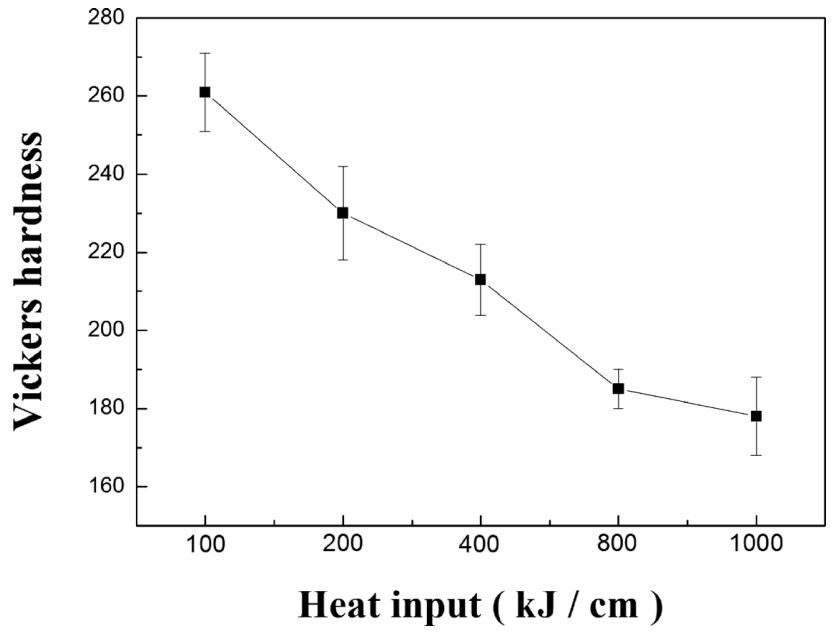

Fig. 6. Variation of vickers hardness with different heat input.

ing fracture. Fracture surface of CGHAZ with $1000 \mathrm{~kJ} / \mathrm{cm}$ reveals brittle fracture mode, in which river pattern appears.

Figure 6 shows Vickers hardness of CGHAZ with high heat input welding thermal cycle decrease with increase the heat input. The lowest hardness value occurs at CGHAZ with $1000 \mathrm{~kJ} / \mathrm{cm}$, which demonstrates appearance of soft microstructure, such as $\mathrm{GBF}$, due to low cooling rate from $800^{\circ} \mathrm{C}$ to $500^{\circ} \mathrm{C}$ at heat input of $1000 \mathrm{~kJ} / \mathrm{cm}$, as shown in Fig. 2(f).

\subsection{Crystallographic Characteristics of CGHAZ}

Figure 7 shows crystallographic characteristics of CGHAZ with heat input of $100 \mathrm{~kJ} / \mathrm{cm}, 400 \mathrm{~kJ} / \mathrm{cm}$ and $1000 \mathrm{~kJ} / \mathrm{cm}$.
Large crystallographic grain size with various orientation exhibited at CGHAZ with $1000 \mathrm{~kJ} / \mathrm{cm}$, as shown in Fig. 7(e). The microstructure with predominant AF has a small crystallographic grain size, as shown in Figs. 7(a) and 7(c), which is defined as a cluster of points sharing the same crystallographic orientation. ${ }^{10)}$ The blue lines stand for high misorientation boundaries of $15^{\circ}$ or more, and red line for low misorientation boundaries of $2-15^{\circ}$ in image quality maps shown in Figs. 7(b), 7(d) and 7(f). The high misorientation grain or packet boundaries can efficiently arrest propagation of cleavage micro-crack, ${ }^{11,12)}$ however, low misorientation boundaries never lead to noticeable deviation of the cleavage crack. ${ }^{12)}$ Effective grain size of CGHAZ with heat input of $100 \mathrm{~kJ} / \mathrm{cm}, 400 \mathrm{~kJ} / \mathrm{cm}$ and $1000 \mathrm{~kJ} / \mathrm{cm}$ measured is about $16.4 \mu \mathrm{m}, 28.5 \mu \mathrm{m}$ and $45.2 \mu \mathrm{m}$, respectively, base on EBSD results.

\section{Discussion}

\subsection{Effect of High Angle Boundaries on Impact Tough- ness of CGHAZ}

High misorientation angle boundaries can effectively arrest micro-cracks propagation, while low misorietation angle boundaries can not be contribute to noticeable deviation of cleavage cracks. ${ }^{11)}$ It is recognized that threshold value of high misorientation boundaries is usually defined at $15^{\circ}$, because the grain boundaries with misorietation more than $15^{\circ}$ can deflect or arrest the cleavage crack propagation according to many literature. ${ }^{11,13)}$ Fraction of high angle boundaries (more than $15^{\circ}$ ) of CGHAZ with heat input of $400 \mathrm{~kJ} / \mathrm{cm}$ is obviously larger than that of $100 \mathrm{~kJ} / \mathrm{cm}$ and 

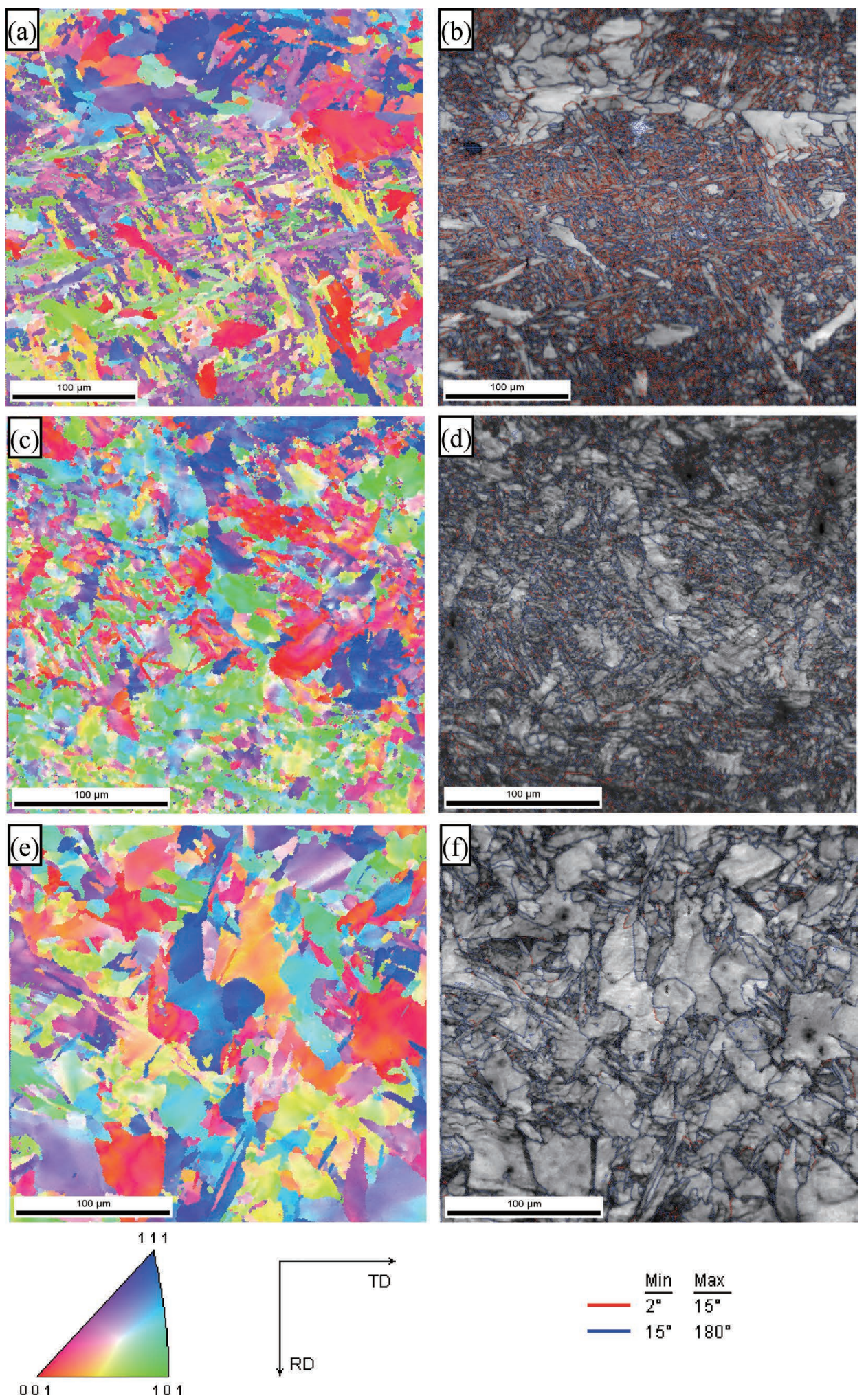

Fig. 7. Crystallographic characteristics of CGHAZ with heat input of (a) and (b) $100 \mathrm{~kJ} / \mathrm{cm}$, (c) and (d) $400 \mathrm{~kJ} / \mathrm{cm}$, (e) and (f) $1000 \mathrm{~kJ} / \mathrm{cm}$, (a), (c) and (e) orientation image maps, (b), (d) and (f) image quality maps.

$1000 \mathrm{~kJ} / \mathrm{cm}$ base on EBSD results, as shown in Fig. 8. Meanwhile, the corresponding impact toughness $(230 \mathrm{~J})$ of CGHAZ with $400 \mathrm{~kJ} / \mathrm{cm}$ is the highest, as shown in Fig. 4. It is worth noting that the fraction of high angle boundaries of CGHAZ with heat input of $1000 \mathrm{~kJ} / \mathrm{cm}$ is slightly larger than that of $100 \mathrm{~kJ} / \mathrm{cm}$, however, the corresponding impact toughness $(120 \mathrm{~J})$ of CGHAZ with $1000 \mathrm{~kJ} / \mathrm{cm}$ is lower than that $(150 \mathrm{~J})$ of $100 \mathrm{~kJ} / \mathrm{cm}$. This result can be explained by taking amount on effective grain size of CGHAZ. Small effective grain size can effectively arrest cracks propagation, improving impact toughness of CGHAZ. During specimen experiencing heat input of $1000 \mathrm{~kJ} / \mathrm{cm}$ welding thermal cycle, grain size become coarsen, especially the nucleation of GBF at prior austenite grain boundaries, because of longer cooling time from $800^{\circ} \mathrm{C}$ to $500^{\circ} \mathrm{C}$. Therefore, the impact toughness is not only related with high angle bound- 


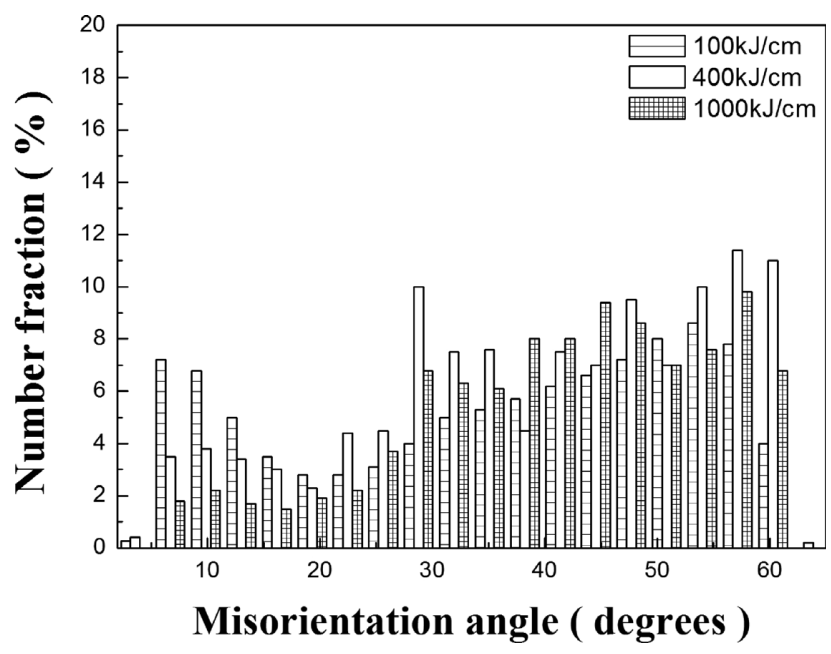

Fig. 8. Distribution of misorientation angle at CGHAZ with heat input of $100 \mathrm{~kJ} / \mathrm{cm}, 400 \mathrm{~kJ} / \mathrm{cm}$ and $1000 \mathrm{~kJ} / \mathrm{cm}$.

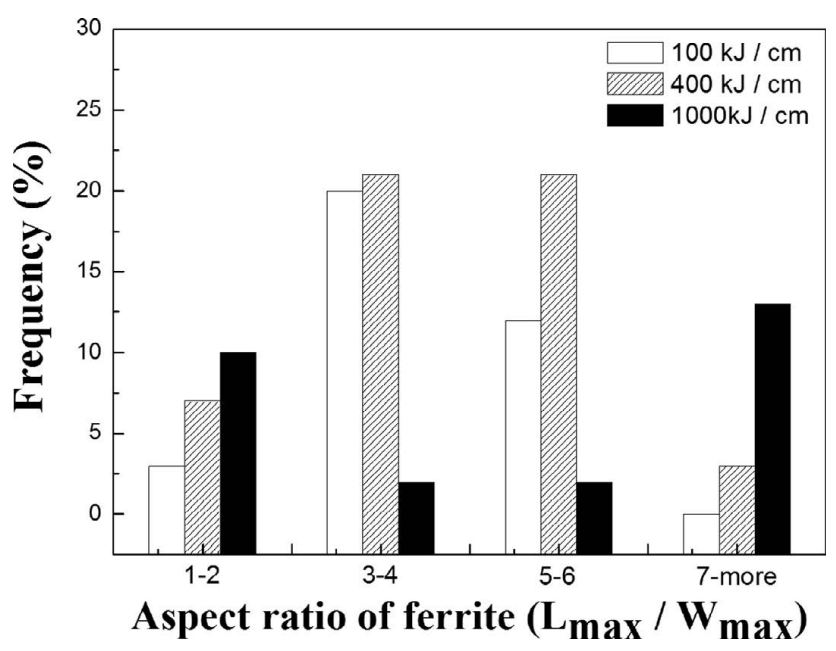

Fig. 9. Distribution of aspect ratio of ferrite inside austenite grain.

aries but also with effective grain size.

\subsection{Effect of Heat Input on AF Transformation at CGHAZ}

Each ferrite inside austenite grain can be characterized individually by its morphological parameters: maximum length $\mathrm{L}_{\max }$, maximum width $\mathrm{W}_{\max }$ and aspect ratio $\left(\mathrm{L}_{\max } /\right.$ $\mathrm{W}_{\max }$ ) measured based on the optical micrographs. AF was defined as ferrite with aspect ratio $\left(\mathrm{L}_{\max } / \mathrm{W}_{\max }>3\right)$ more than 3 in this study. ${ }^{14)}$ The detailed morphologies of ferrite inside austenite grain at CGHAZ with $100 \mathrm{~kJ} / \mathrm{cm}, 400 \mathrm{~kJ} / \mathrm{cm}$ and $1000 \mathrm{~kJ} / \mathrm{cm}$ are shown in Fig. 9. It is found that the number of AF at CGHAZ with $100 \mathrm{~kJ} / \mathrm{cm}$ and $400 \mathrm{~kJ} / \mathrm{cm}$ is higher than that with $1000 \mathrm{~kJ} / \mathrm{cm}$, which is responsible for excellent toughness at CGHAZ. However, much fine AF, aspect ratio more than 7 or more, was observed at CGHAZ with
$1000 \mathrm{~kJ} / \mathrm{cm}$. High supercooling of CGHAZ with $100 \mathrm{~kJ} / \mathrm{cm}$ and $400 \mathrm{~kJ} / \mathrm{cm}$ provided driving force for the $\mathrm{AF}$ transformation during welding thermal cycle, increasing the number of AF. AF transformation is similar to bainite transformation. ${ }^{8)} \mathrm{AF}$ transformation is very fast at some temperature range with shearing mechanism. But the growth of $\mathrm{AF}$ is inhibited owe to small cooling rate at CGHAZ with $1000 \mathrm{~kJ} / \mathrm{cm}$, lacking of driving energy for the further growth of AF.

\section{Conclusions}

(1) Microstructure of CGHAZ with high heat input thermal cycle consisted of high volume fraction of $\mathrm{AF}$ inside grain and GBF at prior austenite grain boundaries. Austenite grain size of CGHAZ increases with heat input increasing due to long holding time at peak temperature.

(2) Excellent impact toughness (more than $100 \mathrm{~J}$ ) of CGHAZ with heat input of $1000 \mathrm{~kJ} / \mathrm{cm}$ was obtained in this experiment. Impact toughness of CGHAZ with $400 \mathrm{~kJ} / \mathrm{cm}$ $(230 \mathrm{~J})$ is the highest, because austenite grain size of CGHAZ with $400 \mathrm{~kJ} / \mathrm{cm}$ favors the development of AF inside grain.

(3) Impact toughness is not only related with high angle boundaries but also with effective grain size. High supercooling of CGHAZ provided driving force for the AF transformation during welding thermal cycle, increasing the number of AF.

\section{Acknowledgements}

The present study is supported by the National Natural Science Foundation of China through grant number: 50834019.

\section{REFERENCES}

1) K. Y. A. Kojima, T. Hada, O. Saeki, K. Ichikawa, Y. Yoshida, Y. Shimura and K. Azuma: Nippon Steel Tech. Rep., 380 (2004), 33.

2) J-H. Shim, Y. W. Cho, S. H. Chung, J-D. Shim and D. N. Lee: Acta Mater., 47 (1999), 2751.

3) Y. Tomita, N. Saito, T. Tsuzuki, Y. Tokunaga and K. Okamoto: ISIJ Int., 34 (1994), 829.

4) F. Chai, C. Yang, H. Su, Y. Zhang, Z. Xu and Y. Yang: Acta Metall. Sin. (English Letters), 21 (2008), 220.

5) F. Ishikawa and T. Takahashi: ISIJ Int., 35 (1995), 1128.

6) N. Rykalin: Calculation of Heat Processes in Welding, Mashgiz, Moscow, USSR, (1960), 4.

7) H. I. Aaronson, G. Spanos, R. A. Masamura, R. G. Vardiman, D. W. Moon, E. S. K. Menon and M. G. Hall: Mater. Sci. Eng. B, 32 (1995), 107.

8) A. A. B. Sugden and H. K. D. H. Bhadeshia: Metall. Trans. A, 20 (1989), 1811.

9) J. L. Lee and Y. T. Pan: ISIJ Int., 35 (1995), 1027.

10) A. F. Gourgues, H. M. Flower and T. C. Lindley: Mater. Sci. Technol., 16 (2000), 26.

11) A. Lambert-Perlade, A. F. Gourgues and A. Pineau: Acta Mater., 52 (2004), 2337.

12) A. Lambert, X. Garat, T. Sturel, A. F. Gourgues and A. Gingell: Scr. Mater., 43 (2000), 161.

13) A. F. Gourgues: Mater. Sci. Technol., 18 (2002), 119.

14) P. Y. Zhang, C. R. Gao and F. X. Zhu: Acta Metall. Sin., 48 (2012), 264. 